\title{
El estudio de las audiencias. Una revisión de las aproximaciones europea y estadounidense
}

Gabriela Pedroza Villarreal $^{1}$

\section{Introducción}

Este trabajo se centra fundamentalmente en la consideración del espacio de recepción de los mensajes de la comunicación masiva, y más precisamente, en cómo se ha revisado desde la teoría la creación de los significados a partir de los mensajes circulantes en los aparatos de distribución o industrias culturales. El estudio de la recepción de los medios masivos de comunicación ha pasado por diferentes etapas y conceptualizaciones, siendo una de ellas la hecha a partir de la propuesta desde la perspectiva de la significación. Se trata entonces de una propuesta para la aproximación al estudio de las audiencias con una estrategia metodológica que rescate la creación simbólica de los receptores, como actividad semantizadora en los circuitos de circulación de los mensajes de los medios masivos de comunicación.

El estudio de las audiencias en sus inicios estuvo dominado por un enfoque funcionalista, que privilegió la idea de que la generación de significados de los mensajes de los medios masivos de comunicación se daba principalmente en el emisor, mientras que el receptor pasivamente recibía los mensajes y los consumía, lo que desarrolló una aproximación metodológica más orientada a la medición cuantitativa. De esta concepción se derivaron las orientaciones que investigaban la posible manipulación de los receptores con base en los mensajes que estaban reflejando las intencionalidades de los generadores de la comunicación masiva.

1. ITESM, campus Monterrey, correo electrónico: gpedroza@itesm.mx. 
Este concepto, lo que produjo es la idea de la recepción más como público que como audiencia, dado que un público lleva asociada la idea de mercado potencial de consumidores. Los emisores podrían entonces orientar las preferencias de los receptores convirtiéndolos en mercados potenciales a los ojos de los anunciantes que sostenían la costosa producción masiva. Estos públicos podrían ser entonces organizados desde esa visión de la emisión por criterios demográficos, para permitir una estratégica planeación de los mensajes y crear necesidades que serían satisfechas con la compra de los productos anunciados.

Por el otro lado, las aproximaciones más recientes intentan demostrar que los receptores son activos participantes en la generación de significados acerca de los mensajes que se distribuyen por los aparatos de las industrias culturales, para lo cual contar a los receptores acomodados por variables como sexo y edad no es suficiente, sino que hay que tomar una aproximacion diferente para desentrañar los mecanismos de semantización de los mensajes de los medios masivos de comunicación como elementos culturales.

Los sentidos de los mensajes de la comunicación masiva surgen de la interacción de emisores, mensajes y receptores en situaciones contextualizadas, lo que demanda la aplicación de técnicas de corte cualitativo, en donde el dato se construye de manera interpretativa. Se trata entonces de una interpretación acerca de las interpretaciones de los mensajes de los medios, mediante procesos de significación complejos y sofisticados realizados tanto por los receptores (televidentes, radioescuchas, espectadores cinematográficos), como por los investigadores y académicos. Es por consiguiente una actividad semiótica relacional, donde el sentido surge en la interacción de los diferentes actores y factores de la comunicación masiva.

En este trabajo se revisa de manera general el concepto de audiencias, según se ha aplicado en investigaciones, desde el enfoque semiótico o interpretativo. Se intenta hacer esta reconstrucción desde la perspectiva anglosajona, con el propósito de establecer cómo en la literatura en inglés proveniente de Reino Unido y Estados Unidos se ha realizado un giro en la conceptualización de los sujetos de las audiencias para que puedan ser considerados reflexivos, y ser analizados como operadores hermenéuticos que generan las interpretaciones de los mensajes, más que simplemente consumirIos pasivamente. Esta reflexividad (Lash y Urry, 1994) en los sujetos no sólo reconoce la actividad que supera las primeras aproximaciones al estudio de la recepción, sino que al mismo tiempo demanda una aproximación metodológica que rescate esos procesos interpretativos, a través también de interpretaciones por parte del investigador. De ahí que se relacione con las interpretaciones de segundo orden propuestas por Giddens (1995). 


\section{Construyendo el objeto: de los públicos a las audiencias}

Para plantear el estudio del proceso de la comunicación de forma más completa y revisar cómo los circuitos de significación que se dan como resultado del mismo generan elementos significativos o semantizadores, es necesario revisar los aportes que se han hecho desde la investigación que se enfoca en las audiencias. Estas aproximaciones teóricas son relativamente recientes y son materia de debates, lo que trae como consecuencia una rica variedad de posiciones y conceptualizaciones acerca del concepto.

La construcción de la categoría de la audiencia de la comunicación ha estado alimentada por diferentes puntos de vista, aunque algunas veces se ha obviado - pór no decir que olvidado-, por el peso tan poderoso de los emisores que organizados como grandes corporaciones controlan la diseminación de los mensajes. El estudio desde los emisores ha sido privilegiado por aproximaciones teóricas como la de la economía política y el imperialismo cultural, que dominaron por algún tiempo los estudios de la comunicación masiva. La recepción sólo en estas teorías es únicamente el complemento a la actividad central, que es la emisión.

Más adelante, y para ampliar la visión de estos enfoques, se hizo imprescindible el rescate de la recepción, que junto con los aportes de la etnografía han sido relevantes en este campo, y sobre todo la inclusión de las audiencias en los estudios de ideología defendidos por los estudios culturales, como se verá en las siguientes páginas.

En la investigación de la comunicación han dominado generalmente dos líneas de pesquisas acerca de la recepción: los enfoques centrados en el comportamiento, que tuvieron más impacto en los estudios realizados en EE.UU., y los enfoques centrados más en el proceso de difusión o diseminación de la ideología que se desarrollaron en Europa principalmente. Esta división ha llevado a ver dichos enfoques como modelos antagonistas y en contraposición uno del otro, cuando en realidad se trata de dos aproximaciones diferentes al fenómeno de la comunicación masiva, y que podrían ser complementarias para aprovechar que en ambas existen elementos de análisis interesantes y útiles para la comprensión del fenómeno de la comunicación masiva, ya sea que provengan de estudios y posiciones teóricas inclinadas más del lado de evaluación de comportamientos (behavior) o de las que se asientan sobre los estudios semiológicos que les dan un tinte más ideológico.

Para organizar mejor esta discusión podemos partir de una división entre los estudios que consideran al receptor de la comunicación como un ente pasivo, carente de actividad, que sólo se limita a completar el proceso de la difusión, y los que, por el contrario, reconocen en él a un sujeto activo, capaz 
no sólo de rechazar sino de participar en los procesos de producción de significado.

Si se considera al sujeto receptor como pasivo se le da al emisor y/o al mensaje una posición privilegiada, incuestionada en términos de Radway (1988). Existe la tendencia de centrar la producción cultural en el momento de la enunciación solamente y se asume que ese momento es siempre necesariamente determinante. Los emisores son centrales en la producción de significados y el mensaje domina el resto del circuito de significación, ya que la audiencia sólo tiene que entender qué se le quiso decir para que el mensaje tenga efecto. Este enfoque conocido como el de efectos ha sido actualmente superado por posiciones más dinámicas, pero en su momento - la temprana década de 1940 - esta aproximación estaba fundamentada en un conductismo casi radical.

Como contraparte, se necesitaba repensar el proceso de la circulación cultural desde un nuevo punto de vista, el punto de vista de que los sujetos receptores son activos productores de la cultura, que construyen narrativas, historias, objetos y prácticas significativas a partir de muchas fuentes y fragmentos de discursos anteriores a ellos. Esto supone que los receptores colaboran y cooperan en el proceso de significación, y que el mensaje no está cerrado en su significación desde el momento en que se emite, sino que es precisamente en la recepción en donde cobra finalmente su sentido. Esto abre la posibilidad a la existencia de significados divergentes, distintos y hasta contradictorios a los fijados por el emisor, ya que el sujeto receptor puede ejercer cierto poder en la interpretación y así resistir a la intención de dominación, si es que la hay, por parte del emisor. En esta línea se encuentran estudios que provienen de dos enfoques: el de usos y gratificaciones y los estudios que enfatizan más los aspectos semióticos.

Los enfoques de efectos y usos y gratificaciones corresponden a una corriente más del lado del positivismo y tienden a ver el proceso de la comunicación como lineal y unilateral, lo que implica una predeterminación de los significados. El enfoque de usos y gratificaciones parece tomar más en cuenta a los receptores, pero cae en una clasificación de los públicos de los mensajes por variables sociodemográficas o de localización geográfica, que de alguna forma están tomando a los receptores sólo como miembros de una división abstracta, creada externamente a los procesos de significación, sin tomar en cuenta a los sujetos que conforman a los públicos. Así, los públicos se van determinando por su edad, sexo, nivel socioeconómico, localización geográfica, etc., lo que reduce y hasta cierto punto predetermina las posibles interpretaciones de los mensajes de los medios masivos por parte de los receptores. Esto generaliza los procesos de significación, desapareciendo las diferencias más sutiles de los procesos de recepción. 
En cambio, la visión de la comunicación como circuitos de significación, en los cuales los diferentes puntos que los componen tienen participación en la creación del significado, se produce por la influencia de la semiótica y del estructuralismo en el estudio de la comunicación. En esta aproximación el sujeto emisor y el receptor comparten por igual la creación de los significados de los mensajes que circulan en los medios de comunicación, y precisamente el significado no está implícito en los mensajes, sino que emerge de la relación situada y contextualizada entre los miembros del circuito comunicativo.

Esta clasificación de enfoques y aproximaciones al estudio de las audiencias es presentada de manera similar por Moores (1993) en la revisión de la literatura sobre el tema de los últimos quince años. Este autor identifica cuatro paradigmas: primero, el de "efectos" donde las audiencias eran pasivas; segundo, aparece la "teoría de Screen"2 en una línea que critica a la anterior, que hace a los receptores del film activos partícipes del proceso de comunicación, como una audiencia ligada al texto del emisor como otra posición del sujeto en la narración, lo que abstrae a la audiencia de la concepción de personas individuales; tercero, el modelo de S. Hall de "codificación/decodificación", donde los receptores son decodificadores de los mensajes de los medios, donde aparecen también las "comunidades interpretativas"; y cuarto, el paradigma de "usos y gratificaciones".

Sobre las teorías que Moores nombra como críticas, que colocan a la audiencia y los receptores en el papel activo, quizá la más extrema es la "teoría de Screen", que se centra en los procesos de significación de la obra cinematográfica y tiene como propósito descubrir los mecanismos simbólicos a través de los cuales los "textos" cinematográficos confieren subjetividad sobre sus lectores, atándolos a la narrativa de la película a través de la producción de posiciones de sujeto, siendo así el "tú" al que se le cuenta la historia fílmica. Hay una serie de problemas con esta teoría, ya que le da demasiada importancia al medio técnico del cine, aparte de que los públicos de los mensajes se vuelven sólo puntos del circuito de significación, confundiendo al sujeto social con un sujeto abstracto.

Por su parte, Stuart Hall y el grupo de estudios de medios del Centre for Contemporary Cultural Studies de la Universidad de Birmingham propusieron y llevaron a cabo estudios de las audiencias activas para probar el modelo de "codificación/decodificación" que intentaba dar cuenta del consumo activo, así como de la producción y organización textual de los sonidos e imágenes de los medios. También buscaba combinar exitosamente intereses semióticos y sociológicos, conectando esos enfoques al estudio de la construcción de significado para incluir perspectivas sobre poder cultural y relaciones sociales.

2. Recibe este título por la referencia a la revista de cine inglesa Screen. 
Se intentaba considerar los contextos sociales donde los sujetos sociales están insertos - como personas reales, concretas-y sobre todo los elementos que podrían tener influencia en la creación del significado de los mensajes de los medios.

\section{La teoría de la articulación}

Radway (1988: 363-4), al hablar de este modelo y la llamada 'teoría de la articulación", explica que es una manera de entender cómo los elementos ideológicos, bajo ciertas condiciones, son coherentes dentro de un discurso, y una manera de preguntar cómo dichos elementos son o no coherentes, en coyunturas específicas, para ciertos sujetos políticos. Esto implica una transformación de cómo se piensa la producción y los usos culturales, ya que esta teoría busca la respuesta a la pregunta de cómo discursos múltiples, públicamente constituidos, se dirigen e interpelan a sujetos sociales, quienes, a su vez, a través de procesos complicados de identificación, activamente se ubican o localizan a sí mismos dentro de al menos varios de esos discursos.

Radway enfatiza dos rasgos de este proceso intrincado y de múltiples niveles. Es esencial entender que los discursos ideológicos son múltiples, producidos dentro y a través de la formación social. Mientras algunos de ellos ciertamente son coherentes y se apoyan mutuamente, otros no. Esta posibilidad de discontinuidad de los discursos subraya las características de un proceso más grande de formación de subjetividades, que destaca la autora: el hecho de que los sujetos sociales activamente participan en el proceso de creación de significación cultural, aunque por esa participación no la controlan completamente ni a sus efectos, y esta participación se hace de forma deliberada, articulando piezas y fragmentos de varios discursos a veces contradictorios. Los sujetos sociales, en efecto, activa y articuladamente participan en el proceso de la producción de subjetividad en el momento en que fraguan articulaciones entre fragmentos ideológicos y discursos más grandes, que son siempre ofrecidos a ellos en razón de la prioridad de la formación social.

Por su parte, Hall (1994), al hablar de su propuesta de "codificación/decodificación", clarifica que el proceso de significación cultural es una totalidad, que él separa analíticamente en dos momentos y los ve además con niveles hacia su interior. Por ejemplo, en la codificación ve dos niveles: el ideológico/cultural, que no tiene fin, es una instancia de las formaciones sociales, es la "significación en general"; y el nivel específico de producción de significados al hacer un artículo cultural o una práctica discursiva concreta, por ejemplo un programa de televisión. Así, estas dinámicas podrían enten- 
derse mejor como procesos de significación de niveles universal y particular en cada caso.

Por su parte, en la decodificación Hall propone tres posiciones: la preferente, la negociada y la oposicional; sólo como posiciones y no como descripciones sociológicas. Precisa que con el concepto de las lecturas preferentes se incorpora la dimensión de poder en el emisor en este modelo o teoría, ya que las audiencias no están al mismo nivel del emisor y de lo que éste desea, espera o pretende como una interpretación sobre otras posibles que se puedan hacer por parte de los receptores, de ahí que se haga una diferencia entre determinismo - más asociado a los modelos lineales de comunicación-y determinación en el mensaje para esta teoría. Hay algo de determinación en la lectura preferente, pero no siempre ésta cumple con su objetivo de provocar una interpretación sobre otras posibles.

Otro concepto interesante de esta teoría de la articulación es el de comunidades interpretativas que se entienden como colectivos que colaboran en la decodificación de los mensajes presentados por los medios masivos. Podría ser, principalmente, la familia, que filtra hasta la exposición a los mismos medios, como también el género que permea la recepción como marcos de interpretación. Precisamente Radway ha realizado estudios de audiencia de mujeres con respecto a los mensajes presentados en la novela rosa (Radway, 1987).

Estas aproximaciones y diversas teorías han enriquecido el estudio de las audiencias de la comunicación masiva, y se podría resumir, como lo hacen Cruz y Lewis (1994) al hacer la revisión por paradigmas centrales, identificando los siguientes: la orientación cultural dentro del marxismo occidental, la crítica americana del liberalismo corporativo, el giro lingüístico en el estructuralismo francés, la elaboración del análisis de la subcultura y análisis de medios conducido por el Centre for Contemporary Cultural Studies, y los campos de la teoría semiótica y el postestructuralismo. Todos estos diferentes puntos de vista ayudaron a abrir el estudio de la significación y su relación con la ideología, instituciones, prácticas culturales y modos de intercambio social.

Estos mismos autores también presentan los giros en la investigación de las audiencias, asociados a la creación de mercados de consumidores del capitalismo de consumo. La expansión industrial, el crecimiento de los suburbios y el impacto de la radio y televisión expandieron y profundizaron la institucionalización de la sociedad de consumo, trayendo como consecuencia el que las audiencias fueran vistas como públicos consumidores, que eran observables por sus comportamientos en estudios de efectos y de usos y gratificaciones. Esta visión, inclinada hacia la concepción de los receptores como consumidores, y no como sujetos productores de significados, fomentó el uso de técnicas de investigación cuantitativistas, como los cuestionarios de encuestas de gran escala para ser analizados con modelos estadísticos y así 
demostrar las preferencias de los públicos y si los mensajes tenían el efecto deseadio en ellos.

Es precisamente el giro hacia lo ideológico, por influencia de la semiótica y el estructuralismo, lo que abrió la posibilidad de utilizar otro tipo de métodos que intentaran algo más que medir. Los modos dominantes de la investigación de audiencias habían confiado en procedimientos hipotético-deductivos para explicar los usos y efectos del contenido manifiesto de los médios. Se puede así clasificar a la investigación de audiencias en cuanto a métodos y técnicas de investigación en dos en los paradigmas que emergieron de dicha tradición: el determinista y el funcionalista. El primero estudiaba los efectos, y el segundo los usos y gratificaciones. Lindolf y Meyer (1987) introducen un tercer paradigma: el interpretativo.

En este paradigma interpretativo se encuentra lo que ellos llaman la investigación cualitativa, donde se encuentran un número de métodos que están diseñados para tener acceso a los dominios naturales en que los actores sociales llevan a cabo sus actividades características. El cuestionamiento de cómo obtener los datos para la investigación social no es nuevo, ya que se trata de argumentar a favor o en contra de dos formas diferentes de aproximarse a la realidad. Este debate entre lo cuantitativo y lo cualitativo, asociado a las dimensiones micro y macro de observación de la realidad social, está presente en toda la investigación social, no nada más en el dominio de los estudios de comunicación. Sin descalificar a ninguna aproximación a la realidad que busca entender y explicar un fenómeno social, el paradigma interpretativo que proponen Lindlof y Meyer es más apropiado para el estudio de cómo se formulan los procesos de significación en la comunicación masiva.

\section{Las audiencias como puntos de encuentro y prácticas sociales}

En otra línea de desarrollo de los estudios de las audiencias, Fiske (1994) discute la posibilidad de estudiar a las audiencias y los discursos que circulan en ellas, ya sean los provenientes de los medios de comunicación o los generados por ellas mismas, como un momento o punto de encuentro donde se crea otro discurso que tiene significación por su particularidad, por su unicidad, al mismo tiempo que logra recrear una estructura u orden de cosas, una organización de la vida y semantización aceptada y hecha común a través de los mundos de vida. En el estudio de las audiencias, y utilizando los grupos de discusión, se encuentran para este autor las dos dimensiones: lo micro y lo macro de la realidad en una investigación. 
Así, el estudio de las audiencias, o de la recepción de los mensajes de los medios masivos de comunicación, por parte de los grupos heteregéneos y dispersos en el espacio que se unen al recibir un programa o un contenido, un grupo que se constituye y se disuelve por la acción de la exposición a un medio, implica el análisis de los procesos simbólicos que fluyen en estas formaciones sociales, y la forma en que esos procesos se concretan en un discurso, en lo que se dice que se vio, escuchó o leyó del medio. Para Fiske, el estudio de la cultura es entrar en el complejo remolino de significaciones que circulan en los distintos niveles y corrientes de la sociedad en general, y particulariza que es en los grupos en donde el analista:

has to select sites of analysis when this circulation of meanings becomes accessible and use them as points from which to theorize the inaccessible undercurrents. Audiences and texts are two of those sites, but neither is sufficient in itself, nor are they together (Fiske, 1994: 193).

Si bien esta posición de Fiske concuerda con la propuesta de Hall y de aquellas que abogan por darle una mayor atención a los procesos semióticos en el estudio de las audiencias, tampoco se puede caer en el extremo de considerar que el significado es un proceso abierto e infinito, y que la polisemia, más que abrir la posibilidad de la participación de los sujetos receptores, es la puerta al caos en la significación. El mismo Hall (citado en Cruz et al., 1994: 263) aplica en su modelo a la ideología como aquello que corta la semiosis infinita del lenguaje, como aquellos marcos de interpretación dinámicos y siempre en construcción que ayudan a la determinación del significado de los mensajes.

Para la observación de cómo operan estas fuerzas de interpretación en los circuitos de significación, los métodos cualitativos han demostrado su utilidad. Siguiendo el argumento de Lindlof y Meyer (1987), se puede decir que hay algunos rasgos distintivos que recomiendan el uso de los métodos cualitativos para el estudio de las audiencias de la comunicación masiva, como son la reflexividad, la contextualidad, la posibilidad de explicación del sistema de significados y el desarrollo de teorías que permiten estos métodos.

Por reflexividad se entiende el involucramiento significativo del acto de investigación tanto como un producto como por un proceso de la vida de todos los días, lo que se conecta con el concepto de dualidad de la estructura propuesto por Giddens (1982). La contextualidad se refiere a las conexiones múltiples entre el fenómeno estudiado y los datos que se pueden obtener de él, conexiones que contribuyen a una evaluación de la validez ecológica de los mismos. Éste es un plano más metodológico, pues es la posibilidad de resolver el conflicto de capturar y traducir en datos lo que se intenta buscar de un 
fenómeno, la cuestión de que si efectivamente se está observando y reflejando en ese dato el fenómeno estudiado.

Al explicar los sistemas de significado, el investigador construye un argumento para las alineaciones simbólicas que motivan o informan el comportamiento patente, lo cual es difícil en el caso de los medios, porque el momento de la recepción dista mucho de la emisión, además de que muchos comportamientos son propios de la esfera de lo privado. En este rasgo o aspecto, lo que surge del uso de la investigación cualitativa aplicada a la comunicación masiva es la idea de competencia, en el sentido de que si asumimos que la acción social está coordinada por constructos intersubjetivos sostenidos en común por los miembros de una comunidad particular, entonces deberá existir comportamiento específico que públicamente demuestre a esos miembros ciertos niveles de competencia en el manejo de significados. Los métodos cualitativos son especialmente útiles en determinar la existencia de valores de competencia indicados como regularidades de comportamiento - con las excepciones que comprueban la regla-, así como también la distribución de esos significados en la sociedad.

El desarrollo de teoría significa partir a la investigación sin instrumentos de medición totalmente desarrollados o estandarizados. El producto teórico de muchos proyectos cualitativos es el desarrollo o refinamiento de tipologías descriptivas que pueden llegar a la explicación. Esto se puede relacionar a lo étic y lo émic de la antropología, donde encontramos que lo émic representa categorías naturales, insistiendo en la inconmensurabilidad de las perspectivas culturales; mientras que lo étic principalmente descansa en observaciones de un investigador ajeno a la situación de observación que se esfuerza en construir explicaciones o sistemas de comportamiento "objetivo" estructurales que atraviesen las culturas.

Ibáñez (1994) indica varias características oposicionales de estos dos conceptos: lo émic es específico e intracultural, se basa en el descubrimiento, es un punto de vista interior, es relativo, es integrador y es un punto de llegada; mientras que lo étic es genérico e intercultural, tiende a la predicción, es exterior, es absoluto y es un punto de partida.

Si lo que se intenta es el entendimiento - no necesariamente la causalidad, que es difícil de comprobar en el comportamiento humano-, los métodos cualitativos nos llevarían a la interpretación y al detalle de lo émic, porque sería difícil construir una audiencia y una recepción que fuera intercultural y predictiva. Los procesos de significación son muy particulares y específicos de ambientes microsociales - como la familia, o el grupo de amigos-, y aún más es todavía difícil precisar los sentidos si se prefiere el nivel individual, lo mismo si se avanza a nivel de grupos y a las prácticas sociales de los mismos, lo que nos hace perder esa dimensión personal. Fenómenos únicos demandan 
el desarrollo de métodos únicos para esos fenómenos, y eso no significa perder la validez de la información obtenida por no ser generalizable.

La meta del estudio de los procesos de significación es el entendimiento de los mismos, para captar las influencias, los elementos, las interacciones, las posiciones relativas. Es hablar de la interpretación a través de la interpretación, en lo que se llama un discurso de segundo orden. Así, la audiencia y la recepción pueden verse como puntos y como discursos, o interdiscursivamente, como plantea Chang (1987), quien ofrece una definición de la audiencia como:

a bundle or bundles of practices embedded in the social circulation/exchange of meaning through which media text are simultaneously constituted and consumed according to the signifying necessity of a particular framework of cultural and ideological reference at different historical moments (Chang, 1987: 660).

Estas prácticas son formadas por los "operadores hermenéuticos", los sujetos sociales, en el espacio interdiscursivo de la formación social, pero no están fijas ni son estáticas, pues se mueven en las coordenadas de tiempo y espacio y por consecuencia son dinámicas. Esta reconceptualización de la audiencia como una práctica implica ver más allá de las diferencias sociodemográficas o de localización geográfica sugeridas por los estudios basados en los enfoques positivistas de efectos y de usos y gratificaciones, revalorando el papel del sujeto en la construcción de los significados, y en consecuencia de la cultura.

Los operadores hermenéuticos seleccionan dentro del rango de discursos que se les presentan en los medios y de otras muy diversas fuentes, como podrían ser los discursos de otras instituciones sociales como la escuela, el centro de trabajo, etc., y construyen lo que vendría a ser propiamente el mensaje de los medios. De esta manera los significados de este mensaje de los medios no están totalmente en el emisor, como tampoco lo están en el receptor, sino que es precisamente la práctica de interacción de lo que se quiso decir, con lo que se entiende que surge el significado específico de los mensajes.

En esta línea de argumentación, tanto Radway como Chang señalan que es en lo popular y en las prácticas de entretenimiento donde se podría observar, a través de técnicas cualitativas propias de la etnografía, estos procesos de construcción de los significados de los medios. En parte porque los medios están centrando su actividad en esa esfera de tiempo libre, creado por la organización del trabajo, llenando de mensajes que intentan entretener, divertir, informar, como también porque es donde los sujetos y/o los grupos pueden elegir quizá con mayor libertad y entonces construir bajo sus propias decisiones el sentido de sus actividades placenteras. 
La construcción por parte de los sujetos, de los significados de las actividades de tiempo libre y de entretenimiento, se hace entonces en lo que Fiske llama una "lucha semiótica y social" (1994: 198), donde las audiencias son prácticas realizadas por formaciones sociales, que aunque se pueden organizar para su estudio en una primera instancia, siguiendo categorías como edad y nivel socioeconómico, provenientes de la investigación con los modelos lineales de comunicación, se constituyen al momento de la creación de los significados como entidades que se van diferenciando y organizando con criterios que surgen de ellos mismos y que no son impuestos exteriormente, entidades activas que hacen mucho más que solamente responder a los mensajes de los medios.

Para intentar explorar estas actividades de la construcción de lo popular en la esfera del entretenimiento y del tiempo libre se hace necesario, como se dijo arriba, echar mano de las técnicas que permitan una observación y traducción de estos momentos del proceso de significación, que en este caso concreto no intentan comprobar, sino describir primero, e interpretar después, estas prácticas. Intentar dibujar entonces una ruta de exploración de este espacio de lo lúdico para los sujetos sociales es echar mano de técnicas de observación en los ambientes "naturales" de interacción y de construcción de significados, en la vida cotidiana y con la búsqueda del dato que desde el mismo sujeto indique por dónde se dirige el proceso de la significación.

Una estrategia que intente entonces rescatar desde los sujetos sociales la creación de discursos de construcción de significados implica crear espacios donde ellos puedan expresarse, y los grupos de discusión aparecen como el camino adecuado. Además se podrían intentar otras técnicas, como la observación participante, que arrojaran datos sobre cómo los sujetos van elaborando en esos espacios de descanso los circuitos de significación que crean los discursos de los medios de comunicación.

Una vez recogida esa información, el investigador tiene que darse a la tarea de la interpretación de segundo orden, a fin de ir al mismo tiempo reconstruyendo los procesos de significación y buscar las regularidades o los elementos comunes que permitieran una explicación más generalizable que rebasara el ámbito de lo particular y micro-episódico. Esta tarea no es fácil, ni mucho menos asequible en periodos de corto plazo, sino que son tareas de largo alcance, de detalle y minuciosidad, pues el intento de capturar esa explicación implica cubrir todo el espectro de los discursos que se combinan y se mezclan, así como el reconocimiento de los procesos más amplios de significación que se suceden en las formaciones sociales. Esa dificultad no es sinónimo de imposibilidad, es más que todo el reto de la investigación en el ámbito de los procesos de significación en la comunicación masiva inmersa en la sociedad. 


\section{Bibliografía}

Chang, Briankle G. (1987), "Deconstructing the Audience: Who Are They and What Do We Know About Them", en Communication Yearbook, Margaret L. McLaughlin (edit.), Newbury Park, Beverly Hills, Londres, Nueva Delhi, Sage Publications, núm. 10.

Cruz et al. (1994), "Reflections Upon the Encoding/Decoding Model: An Interview with Stuart Hall", en Cruz, Jon y Justin Lewis (edits.) Viewing, Reading, Listening. Audiences and Cultural Reception, Boulder, San Francisco, Oxford, Westview Press.

Cruz, Jon y Justin Lewis (1994), "Introduction", en Viewing, Reading, Listening, Audiences and Cultural Reception, Boulder, San Francisco, Oxford, Westview Press.

Fiske, John (1994), “Audiencing. Cultural Practice and Cultural Studies”, en Handbook of Qualitative Research, Norman K. Denzin e Yvonna S. Lincoln (edits.), Sage Publications, Thosuand Oaks, Londres, New Delhi.

Ibáñez, Jesús (1994), El regreso del sujeto, Siglo XXI Editores, México, España.

Lash, Scott y John Urry (1994), Economies of Signs and Space, Londres, Thousand Oaks, New Delhi, Sage Publications.

Lindlof, Thomas R. y Timothy P. Meyer (1987), "Mediated Communication as Ways of Seeing, Acting, and Constructing Culture: The Tools and Foundations of Qualitative Research", en Natural Audiences: Qualitative Research of Media Uses and Effects, Thomas Lindlof (editor), Nueva Jersey, Ablex Publ. Corp. Norwood, pp. 1-31.

Moores, Shaun (1993), Interpreting Audiences. The Ethnography of Media Consumption, Londres, Thousand Oaks, Nueva Delhi, Sage Publications. Nightingale, Virginia (1999), El estudio de las audiencias. El impacto de lo real, Barcelona, Buenos Aires, México, Paidós.

Radway, Janice (1987), Reading the Romance: Women, Patriarchy and the Popular Literature, Londres, Verso.

- (1988), "Reception Study: Ethnograpy and the Problems of Dispersed Audiencies and Nomadic Subjects", en Cultural Studies, vol. 2, núm. 3, octubre de 1998, pp. 359-76. 